\title{
Celebrando mais um número da SMAD
}

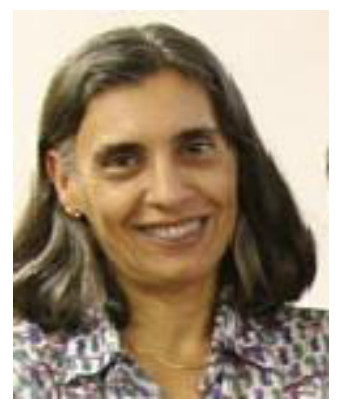

É com grande satisfação que apresentamos esse fascículo da revista SMAD, o de número 3 que fecha o ano de 2012. O trabalho de editoração de um periódico não é fácil como já mencionado em outros editoriais e por tantos outros editores.

Em meio às exigências de publicação que marcam o trabalho nas instituições de ensino superior do país, em especial aquelas que têm programas de pós graduação, é preciso ter clareza quanto à qualidade das pesquisas produzidas. Diz o ditado que a pressa é inimiga da perfeição e temos assistido a uma produção enorme de trabalhos muitas vezes carentes de aprofundamento e de possibilidade de vir acrescentar conhecimento às áreas em que se inserem. Isso é particularmente preocupante na área de SM.

Como membro da comissão editorial desta revista percebo que caminhamos entre a meta de firmarmo-nos como veículo de divulgação e ao mesmo tempo avançar nos patamares de qualidade.

Penso que esforços têm sido feitos nos dois sentidos, mas ainda há muito o que fazer e por isso contamos com nossos colegas que encaminham os resultados de suas pesquisas, com o trabalho dos consultores ad hoc, da própria comissão editorial e com os leitores que acessarão os trabalhos e oferecerão índices do impacto destes. É uma cadeia complexa de ações e de conexões em que todos são atores importantes.

Neste número contamos com sete trabalhos. A maior parte deles aborda o problema do consumo de substâncias psicoativas entre estudantes universitários e estudantes de nível médio. PERFIL DA UTILIZAÇÃO DE DROGAS LÍCITAS E ILÍCITAS POR UNIVERSITÁRIOS DE UMA INSTITUIÇÃO PRIVADA, dos autores Rizângela Lyne Mendes de Freitas, Danelle da Silva Nascimento, Rivelilson Mendes de Freitas, Gláucio Barros Saldanha, Roberta Mayara de Moura Rocha e Pauline Sousa dos Santos; DEPRESSÃO E CONSUMO DE ÁLCOOL EM ESTUDANTES DE UMA ESCOLA PÚBLICA EM COATZACOALCOS VERACRUZ dos autores Brenda Alicia Hernández Cortaza, Leticia Cortaza Ramírez e Moacyr Lobo da Costa Junior e O USO DE SUBSTÂNCIAS PSICOATIVAS POR ESTUDANTES DO ENSINO FUNDAMENTAL E MÉDIO: UMA REVISÃO SISTEMÁTICA, dos autores Flávia Batista Portugal e Marluce Miguel de Siqueira.

Focalizando o usuário de drogas, o trabalho A VISÃO DE ADOLESCENTES USUÁRIOS E NÃO USUÁRIOS DE MACONHA SOBRE SEUS PROBLEMAS DE COMPORTAMENTO dos autores Margareth da Silva Oliveira, Maísa dos Santos Rigoni, Nathália Susin, Marcela Bortolini, Camila Guimarães Dornelles e Luciana Bohrer Zanetello aborda a avaliação que adolescentes atendidos em um serviço de assistência à saúde mental, usuários e não usuários de maconha, fazem de seus problemas de comportamento.

O trabalho ESPOSAS DE ALCOOLISTAS: RELAÇÕES FAMILIARES E SAÚDE MENTAL, dos autores Joseane de Souza, Ana Maria Pimenta Carvalho, Maycoln Lêoni Martins Teodoro aborda o impacto da convivência com o companheiro usuário abusivo de álcool.

O trabalho intitulado ESTRATÉGIAS DE ENFRENTAMENTO ÀS CARGAS DE TRABALHO DE ENFERMEIROS DE UNIDADE DE EMERGÊNCIA/PR, dos autores Júlia Trevisan Martins, Maria Cristina Cescatto Bobroff, Renata Perfeito Ribeiro, Vanessa Monique Luiz Costa, Alexandrina Aparecida Maciel Cardelli eMara Lúcia Garanhani aborda a saúde mental dos profissionais enfermeiros atuantes em unidades de urgência e emergência.

Outro artigo, CONCEITOS E PRECONCEITOS SOBRE TRANSTORNOS MENTAIS dos autores Maria Rosilene Cândido Moreira, Edina Araújo Rodrigues Oliveira, Claudete Ferreira de Souza Monteiro, José Ronildo da Costa, Geórgia Salanne Rodrigues Benício, Flora Lia Leal da Costa,discute as concepções de transtornos mentais por um grupo de trabalhadores em instituição de ensino superior. Trata-se de importante discussão que usualmente é trazida no contexto da sociedade mais ampla e aqui aborda profissionais de instituições formadoras de recursos humanos para atuação em saúde mental.

Boa leitura! 
